(NP,IT)Proceedings, 8th International Meeting on Radiation Prcessing, Beijing, China, September 14 19, 1992, Joumal of Rad. Phys. Chem.

\author{
19. 1992, Joumal of Rad. Phys. Chem.
}

ANK/CP--76176

DE93 002991

\title{
EARLY EVENTS IN RADIATION CHEMISTRY AND IN PHOTOIONIZATION
}

\author{
A. D. TRIFUNAC, D. M. LOFFREDO and A.-D. LIU ${ }^{\dagger}$
}

Chemistry Division, Argonne National Laboratory, Argonne IL 60439 USA

\section{DISCLAIMER}

This report was prepared as an account of work sponsored by an agency of the United States Government. Neither the United States Government nor any agency thereof, nor any of their employees, makes any warranty, express or implied, or assumes any legal liability or responsibility for the accuracy, completeness, or usefulness of any information, apparatus, product, or process disclosed, or represents that its use would not infringe privately owned rights. Reference herein to any specific commercial product, process, or service by trade name, trademark, manufacturer, or otherwise does not necessarily constitute or imply its endorsement, recommendation, or favoring by the United States Government or any agency thereof. The views and opinions of authors expressed herein do not necessarily state or reflect those of the United States Government or any agency thereof.

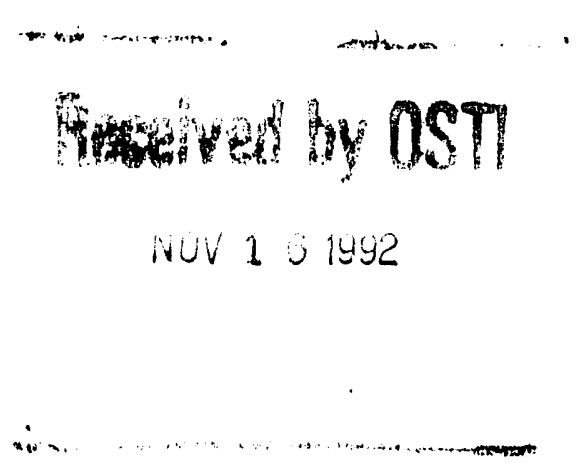

tWork performed under the auspices of the Office of Basic Energy Sciences, Division of Chemical Science, US-DOE under contract number W-31-109-ENG-38. 


\title{
EARLY EVENTS IN RADIATION CHEMISTRY AND IN PHOTOIONIZATION
}

\author{
A. D. TRIFUNAC, D. M. LOFFREDO and A.-D. LIU' ${ }^{\dagger}$ \\ Chemistry Division, Argonne National Laboratory, Argonne IL 60439 USA
}

\begin{abstract}
Real-time studies of aliphatic and aromatic hydrocarbons by pulse radiolysis and laser photoionization reveal the chemistry of the ionic species in the condensed phase. The occurrence of radical cation reactions with solvent molecules provides the core mechanism capable of explaining a wide range of observations in photoionization and radiation chemistry. The study of products and transients in photoionization of aromatic solutes in hydrocarbon and alcohol solvents illustrates several details of this "high-energy" chemistry. A reaction pathway involving ion-molecule reaction of excited ions is indicated for a series of polycyclic aromatic hydrocarbons photoionized using intense excimer laser ( 248 and $308 \mathrm{~nm}$ ) pulses in hydrocarbon and alcohol solutions. We have found that condensed-phase ion-molecule reactions in radiolysis are ubiquitous and we speculate on their overall role in hydrocarbon radiolysis.
\end{abstract}

\section{KEYWORDS}

Radical cations, ion-molecule reactions, photoionization, radiolysis, flash photolysis, conductivity, prod uct studies

\section{ION-MOLECULE REACTIONS IN PHOTOIONIZATION}

Understanding of the early events in radiation chemistry is relevant to chemical consequences of radiation in chemical, biological, and technological applications. Our ability to directly observe and sort out the various transient intermediates produced by ionizing or photoionizing radiation is closely coupled to the development of better experimental tools.

Studies over the last decade have revealed the importance of ionic species in early chemical events induced by ionizing radiation. Indeed, the first observable species in condensed-phase pulse radiolysis of nonpolar solutions is the initial charge pair. Radiation chemistry is the description of the chemical consequences of this charge-pair production. The solvation of ions and their reactions and transformations dominate the chemical landscape of radiation chemistry. While the chemical role of excited neutral species is often in voked, appreciation of the importance of ion chemistry is increasing.

Recently we have initiated a systematic study of the energy dependence of ion chemistry. Several new techniques and ultrafast tools of radiolysis and photoionization were used to characterize the ionic species in real time. Samples were excited using nanosecond pulses of UV light from excimer lasers. Flash photolysis, time-resolved DC conductivity as well as product studies were carried out (Trifunac, $a$ al.,1992; Loffredo et al., in press).

ton leave from Beijing Normal University, Beijing, China. 
These studies address several questions: What happens to the excess energy input into the condensed phase system above that needed to cause ionization? What are the highly excited species and processes that may be so induced? Our studies reveal that a new reaction channel opens up; that is, ion-molecule reactions of excited ions become important. Thus, we modify the accepted scheme of photoionization to in clude an ion-molecule reaction of the excited radical cation $\mathrm{AH}^{+*}$ :

$$
\begin{gathered}
\mathrm{AH} \stackrel{2 \mathrm{hv}}{\longrightarrow} \mathrm{AH}^{+*}+\mathrm{e}^{-} \\
\mathrm{AH}^{+*}+\underset{\text { solvent }}{\mathrm{RH}} \rightarrow \mathrm{A} \cdot+\mathrm{RH}_{2}^{+}
\end{gathered}
$$

We have carried out time-resolved and product studies of photoionization of aromatic solutes AH in both hydrocarbon and alcohol solvents, which we describe below.

\section{Product Studies}

Photolysis of several aromatic solutes in hydrocarbons and in alcohols reveals the involvement of aryl radicals and solvent-radical-derived products. The following schemes are illustrative of the photoionization of naphthalene and anthracene in cyclohexane.
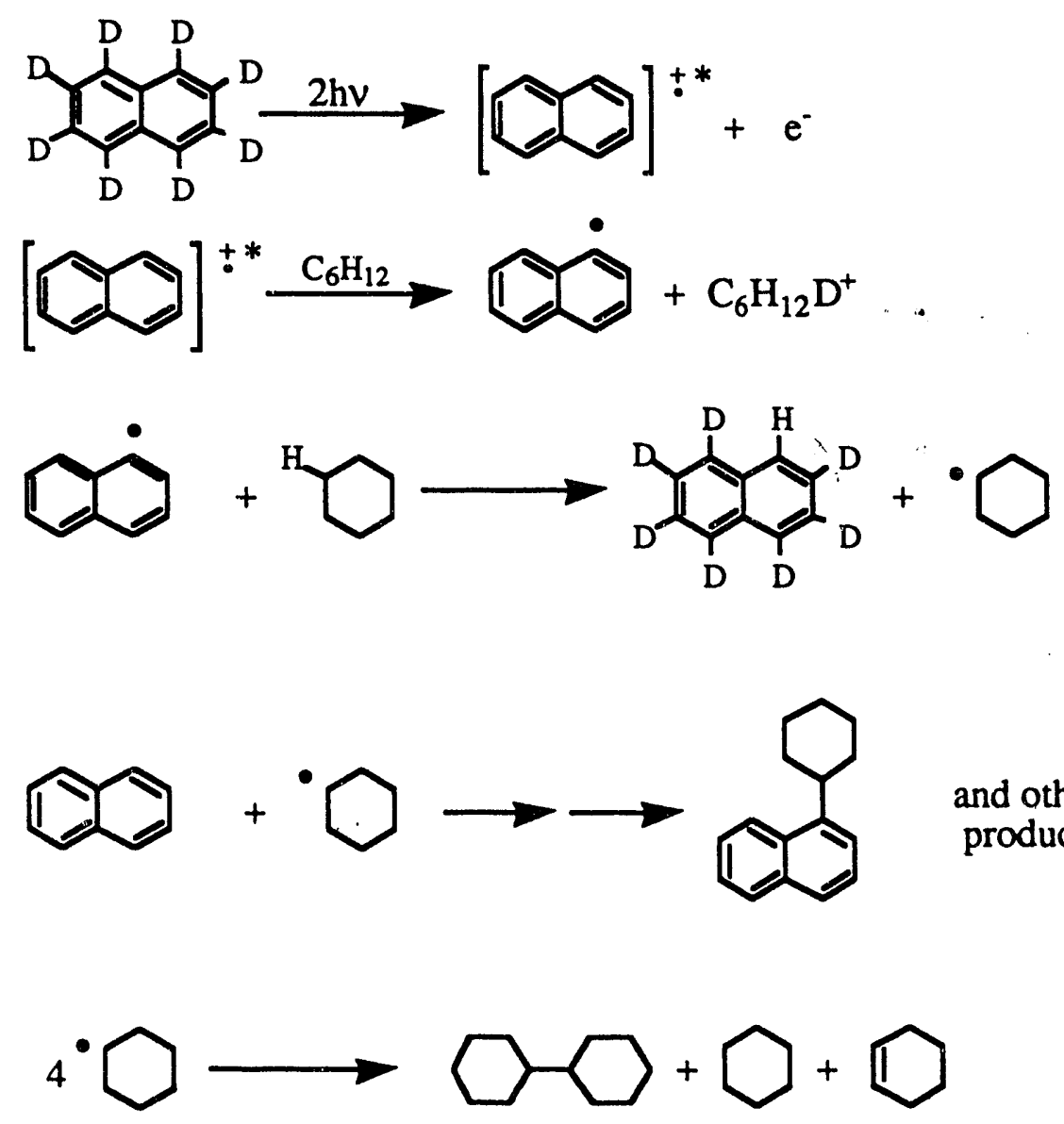

and other products

Scheme 1. Aryl and cyclohexyl radical formation and subsequent reactions with isotopically labeled naphthalene.

The products identified include: $\mathrm{H}_{2}, \mathrm{HD}$, bicyclohexyl, cyclohexene and the coupling products as in reaction (d). With the perdeuterated solute, the incorporation of a single hydrogen is monitored. This provides a direct measure of aryl radical formation. The extent of the reaction is greater in alcohols than alkanes, as illustrated by anthracene data in Table and Scheme 2. 
Table: Product and isotope distribution after photolysis of perdeuterated polycyclic aromatic hy drocarbons in various solvents at 248 and $308 \mathrm{~nm}$.

\begin{tabular}{|c|c|c|c|c|c|}
\hline substrate/solvent & $\begin{array}{l}\text { parent } \\
\text { ion }\end{array}$ & $\begin{array}{l}\text { isotopic } \\
\text { ion }\end{array}$ & $\Delta \%^{\mathrm{a}}$ & $\begin{array}{l}\% \text { yield of } \\
\text { cyclohexyl } \\
\text { radicals }^{b}\end{array}$ & $\begin{array}{c}\% \\
\text { substrate } \\
\text { consumed }\end{array}$ \\
\hline \multicolumn{6}{|l|}{$248 \mathrm{~nm}$} \\
\hline naphthalene/cyclohexane & $\mathrm{C}_{10} \mathrm{H}_{8}$ & $\mathrm{C}_{10} \mathrm{H}_{7} \mathrm{D}$ & 0.1 & $\overline{10.9}$ & $\overline{43}$ \\
\hline naphthalene/cyclohexane(d12) & $\mathrm{C}_{10} \mathrm{H}_{8}$ & $\mathrm{C}_{10} \mathrm{H}_{7} \mathrm{D}$ & 8.0 & 11.0 & 41 \\
\hline naphthalene(d8)/cyclohexane & $\mathrm{C}_{10} \mathrm{D}_{8}$ & $\mathrm{C}_{10} \mathrm{HD}_{7}$ & 7.9 & 11.4 & 44 \\
\hline naphthalene(d8)/isopropanol & $C_{10} D_{8}$ & $\mathrm{C}_{10} \mathrm{HD}_{7}$ & 8.6 & - & - \\
\hline p-terphenyl(d14)/cyclohexane & $\mathrm{C}_{18} \mathrm{D}_{14}$ & $\mathrm{C}_{18} \mathrm{HD}_{13}$ & 4.7 & - & - \\
\hline anthracene(d8)/cyclohexane & $\mathrm{C}_{14} \mathrm{D}_{10}$ & $\mathrm{C}_{14} \mathrm{HD}_{9}$ & 8.0 & - & 83 \\
\hline anthracene(d8)/isopropanol & $\mathrm{C}_{14} \mathrm{D}_{10}$ & $\mathrm{C}_{14} \mathrm{HD}_{9}$ & 14.8 & - & 65 \\
\hline \multicolumn{6}{|l|}{$308 \mathrm{~nm}$} \\
\hline naphthalene(d8)/cyclohexane & $\mathrm{C}_{10} \mathrm{D}_{8}$ & $\mathrm{C}_{10} \mathrm{HD}_{7}$ & 2.2 & 3.2 & 26 \\
\hline anthracene(d8)/cyclohexane & $\mathrm{C}_{14} \mathrm{D}_{10}$ & $\mathrm{C}_{14} \mathrm{HD}_{9}$ & 0.6 & - & 33 \\
\hline anthracene(d8)/isopropanol & $\mathrm{C}_{14} \mathrm{D}_{10}$ & $\mathrm{C}_{14} \mathrm{HD}_{9}$ & 1.9 & - & 30 \\
\hline
\end{tabular}

$\mathrm{a} \Delta \%$ is the difference between the relative abundances of the isotopic ion before and after irradiation, taking into account the contribution of carbon-13 isotopes.

bFour times the bicyclohexyl yield, divided by the initial concentration of aromatic substrate (the bicyclohexyl yield is assumed to be representative of the overall radical yield).

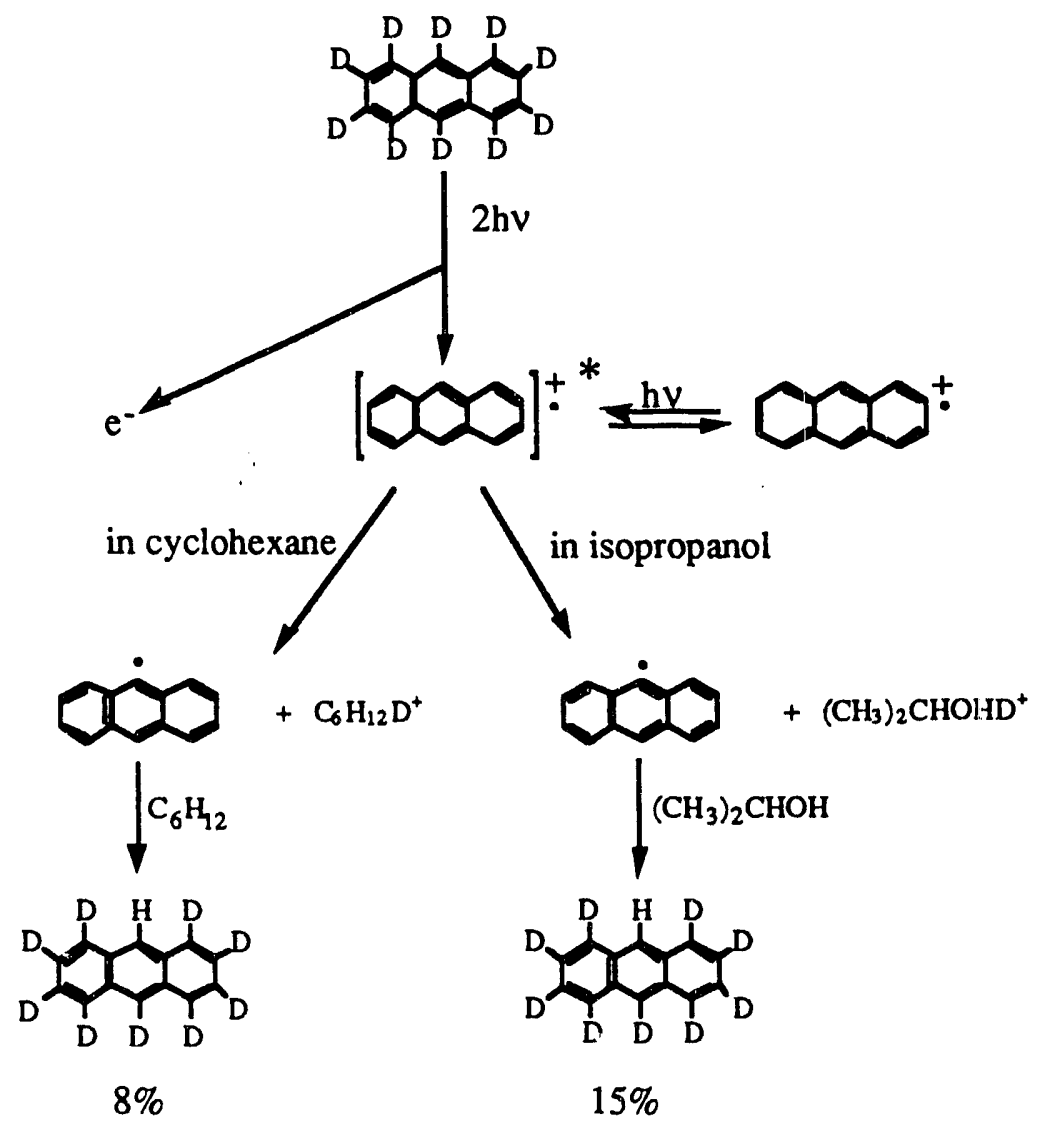

Scheme 2. Aryl radical formation during flash photolysis $(248 \mathrm{~nm})$ of d10-anthracene in cyclohexane or isopropanol. 
The only other conceivable reaction pathway giving rise to aryl radicals is neutral excited state homolysis:

$$
\mathrm{AH}^{* *} \stackrel{2 \mathrm{hv}}{\longrightarrow} \mathrm{A} \cdot+\mathrm{H} \cdot
$$

Several results of the product studies offer strong evidence that this is not an important process: (1) The $\mathrm{H}_{2}$ yield decreases with the addition of aromatic solute to a hydrocarbon solvent; $i$. e., the small yield of $\mathrm{H}_{2}$ from solvent photolysis (Schwarz et al., 1981) decreases even further when an aromatic solute be comes the main species absorbing light. (2) In appropriately isotopically labelled solute-solvent systems, substantial HD yield would be indicative of the generation of $\mathrm{H} \cdot$ atoms. If solvent radicals were formed by reaction with $\mathrm{H} \cdot$ atoms (abstraction), then the $\mathrm{HD}$ fraction of the $\left(\mathrm{H}_{2}+\mathrm{HD}\right.$ ) yield would be $-37 \%$, while a value of only $1.5 \%$ is found. (3) The effect of solvent polarity and proton affinity is consistent with an ionic process; one would not expect the homolysis of highly excited neutral species to be strongly solvent dependent. (4) The effect of $\mathrm{SF}_{6}$ on product formation is also indicative of an ion reaction. Electron scavenging by $\mathrm{SF}_{6}$ increases the lifetime of radical cations and thus increases the ionmolecule reaction yield. One would not expect $\mathrm{SF}_{6}$ to enhance neutral excited state homolysis. On the contrary, one would expect some slight decrease via the excited state quenching by $\mathrm{SF}_{6}$. We conclude that neutral excited state homolysis cannot be a significant contributor to the aryl radical yield in these photoionization experiments.

\section{Transient Absorption and Conductivity Studies}

Transient absorption spectroscopy was used to observe aromatic radical cations in alcohols and hydrocarbon solvents, as well as the solvated electron in alcohols. The electrons and free ions in hydrocarbon sol vents were detected by DC conductivity. The transient species were generated by 248 $\mathrm{nm}$ and $308 \mathrm{~nm}$ laser photolysis (Liu et al., in press).

The study of the relative yields of electrons and aromatic cations reveals that they diverge with increasing energy of excitation. With increasing photon energy and photon flux the electron yield (and free ion yield) increases, while the yield of radical cations decreases. This is very easily seen in alcohol solutions where at high light intensities one observes a dramatic difference of electron and radical cation yields (Figure).

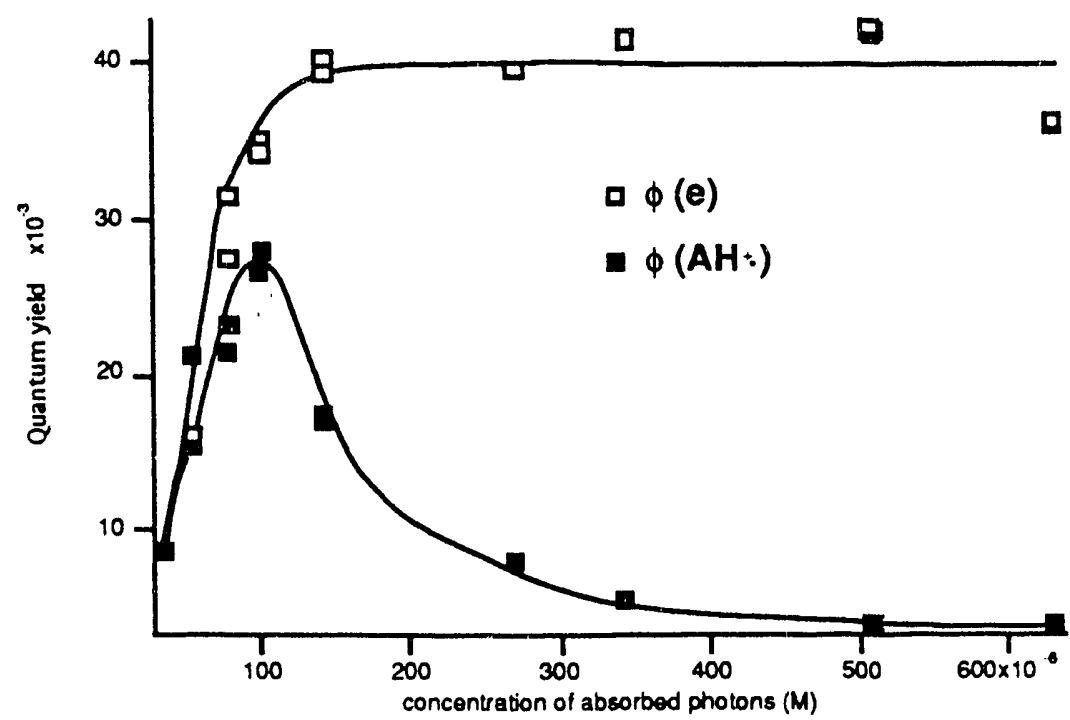

Figure Quantum yields of the solvated electron and anthracene radical cation as a function of laser intensity during $248 \mathrm{~nm}$ laser flash photolysis of $5 \times 10^{-5} \mathrm{M}$ anthracene in 2propanol.

This suggests that while some processes are biphotonic (two sequential photons), there is also a "three-" photon process in which the third photon excites a radical cation.

$$
\mathrm{AH}^{+} \stackrel{\mathrm{hv}}{\longrightarrow} \mathrm{AH}^{+*}
$$


This is also evident in some product studies, e.g., the presence of $\mathrm{SF}_{6}$ extends the aromatic radical cation lifeime, resulting in an increase in the chemical yield of products from ion-molecule reactions of excited radical cation species.

The flash photolysis and conductivity studies are consistent with the idea that neutral excited state homol ysis is not an important process. The divergence of the electron and radical cation yields with increasing photon energy and flux is an important prediction of the proposed mechanism (eq. 2) involving ionmolecule reactions of excited aromatic radical cations that is borne out in these studies.

\section{ION-MOLECULE REACTIONS IN RADIOLYSIS}

The amount of experimental data available on radiolysis of hydrocarbons is considerable but does not provide sufficient detail. Few comprehensive studies of early events and transient species have been carried out. Studies of static systems, i.e., low temperature matrix work, and several scavenging studies have provided some insights into the role of radical cations in hydrocarbon radiolysis. However, very little information can be found on the relative importance of different processes in different hydrocarbons. The data on the overall product distributions do not provide sufficient insight.

We have examined several aspects of early events in radiolysis of hydrocarbons and have outlined some features of the overall mechanism (Sauer, Jr. et al., 1991). Here we extend our ideas to a more general radiolysis mechanism, which is closely related to the mechanism discussed in photoionization:

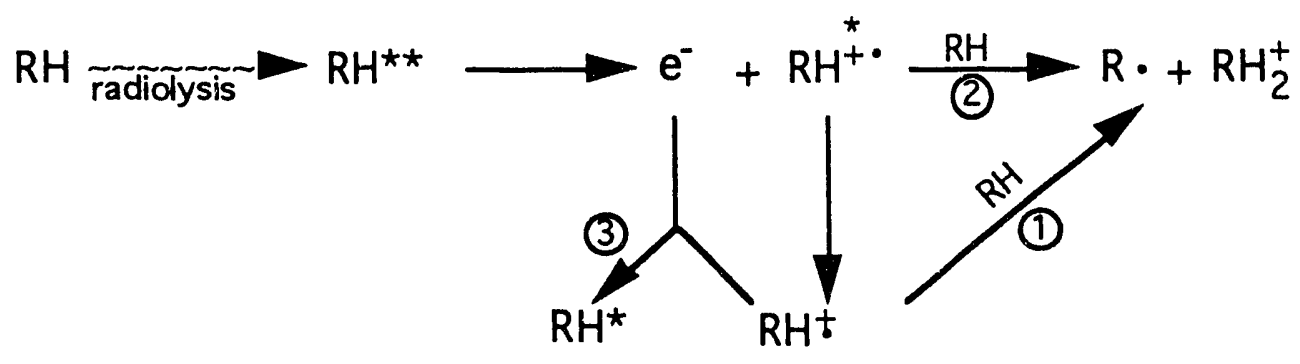

Scheme 3. Early events in radiolysis of hydrocarbons. Ion-molecule reactions.

We have examined several processes in this scheme. Our time-resolved studies of alkane radical cations by time-resolved Fluorescence Detected Magnetic Resonance (FDMR) have allowed us to identify and characterize many alkane radical cations. We have also found that ion-molecule reactions (reaction 1) of (relaxed) radical cations $\mathrm{RH}^{\dagger}$ are facile and widespread (Trifunac et al., 1989; Werst and Trifunac, 1991). Picosecond emission studies in our lab have measured lifetimes of alkane radical cations in cyclohexane and $n$-hexane radiolysis (Sauer et al., 1991). Ion-molecule reactions of alkane radical cations (reaction 1), while surprisingly fast, are not fast enough to compete with the geminate recombination (reaction 3 ).

Other studies by time-resolved EPR (Werst and Trifunac, 1987) and by picosecond absorption methods (Tagawa, et al., 1989) in pulse radiolysis reveal very fast radical $\left(R^{\circ}\right)$ production in hydrocarbon radioly sis. Picosecond emission studies in our laboratory have found that there is a difference in electron and fluorescence scavenging (Jonah and Sauer, Jr., 1989), suggesting that some alkane radical cations undergo very fast transformation into species that do not recombine with electrons (reaction 3 ) to give rise to fluorescence.

These observations can all be explained by considering that, in reaction 2 of Scheme 3, a fast ionmolecule reaction of an excited radical cation $\left(\mathrm{RH}^{+*}\right)$ occurs on the picosecond time scale. This is also consistent with the ideas expressed in the past work in radiolysis, when it was speculated that only a fraction of ions recombine to give rise to excited species (Schwarz et al., 1981). Other observations reveal that there are different electronic states of radical cations (Barnabas and Trifunac, 1991; Lee and Lipsky, 1985). So far, we do not know what their chemistry is. Our studies reveal that ion-molecule reactions are widespread in condensed-phase radiolysis. The question that remains is to what extent do these ion-molecule reactions contribute to the overall products of radiolysis? 


\section{SUMMARY}

The study of photoionization induced by intense UV pulses of light reveals a common reaction pathway involving ion-molecule reactions of excited ions of aromatic solutes in hydrocarbon and alcohol solutions. This reaction pathway is often the main route of destruction of the aromatic solutes in these systems.

Several observations in radiolysis suggest that analogous ion-molecule chemistry may be important in the radiolysis of hydrocarbons. It is well known that such processes are important in the radiolysis of water and alcohols.

While many qualitative details of the proposed ion-molecule reaction pathways are still being examined, the ion-molecule reaction of radical cations is the key concept needed to explain chemistry occurring above the ionization threshold.

\section{Acknowledgment}

Work performed under the auspices of the Office of Basic Energy Sciences, Division of Chemical Science, US-DOE under contract number W-31-109-ENG-38.

\section{REFERENCES}

Barnabas, M. V. and A. D. Trifunac (1991). Electronic states of cis- and trans-decalin radical cations in zeolites. Chem. Phys. Lett. 187, 565-570.

Jonah, C. D. and M. C. Sauer Jr. (1989). Unification of electron scavenging and fluorescence quenching results in cyclohexane radiolysis - evidence for the importance of excited ions. Radiat. Phys. Chem. 34, 497-501.

Lee, K. and S. Lipsky (1985). The photoionization yield and electron thermalization range spectra of $\mathrm{N}, \mathrm{N}, \mathrm{N}^{\prime}, \mathrm{N}^{\prime}$-tetramethyl-p-phenylenediamine (TMPD) in tetramethylsilane. J. Chem.Phys., $\underline{\mathbf{2}}$, 3850-3655.

Liu, A.-D., M. C. Sauer, Jr., D. M. Lofffredo and A. D. Trifunac, in press,. Transient Absorption Spectra of Aromatic Radical Cations in Hydrocarbon Solutions. J. Photochem. Photobioll.

Loffredo, D. M., A.-D. Liu and A. D. Trifunac, in press,. Photoionization of Polycyclic Aromatic Hydrocarbons in Alkane Solutions: "High Energy" Chemical Pathways. Rad. Phys .Chem.

Sauer, Jr., M. C., C. D. Jonah and C. A. Naleway (1991). Study of the reactions of geminate ions in irradiated scintillator, hydrocarbon solutions using recombination fluorescence and stochastic simulations. J. Phys. Chem, 95, 731-740.

Sauer, Jr., M. C., D. W. Werst, C. D. Jonah and A. D. Trifunac (1991). Primary events in hydrocarbon radiolysis: real-time studies of radical-cation chemistry.Rad. Phys. Chem. 37, 461-467.

Schwarz, F.P., D. Smith, S. G. Lias and P. Ausloos (1981). The fluorescence and photofragmentation of liquid saturated hydrocarbons at energies above the photoionization threshold. J. Chem. Phys. 75 , 3800-3808.

Tagawa, S., N. Hayashi, Y. Yoshida, M. Washio and Y. Tabata (1989). Pulse radiolysis structures on liquid alkanes and related polymers. Radiat. Phys. Chem. 34, 503-511.

Trifunac, A. D., D. W. Werst and L. T. Percy (1989). Proton transfer in alkane radical cations. FDMR pulse radiolysis study. Radiat. Phys. Chem., 34, 547-552.

Trifunac, A. D., A.-D. Liu and D. M. Loffredo (1992). Condensed phase studies of radical ions in photoionization and radiolysis. In: Dynamics and Mechanisms of Photoinduced Transfer and Related Phenomena, (N. Mataga, T. Okada and H. Masuhara, eds.), pp. 259-274. Elsevier Science Publishers.

Werst, D. W. and A. D. Trifunac (1987). Radical formation in the pulse radiolysis of liquid cyclohexane. Time-resolved EPR-scavenging study. Chem. Phys. Lett. 137, 475-481.

Werst, D. W. and A. D. Trifunac (1991). Study of radical ions in the condensed phase by fluorescencedetected magnetic resonance. J. Phys. Chem., 95, 3466-3477. 

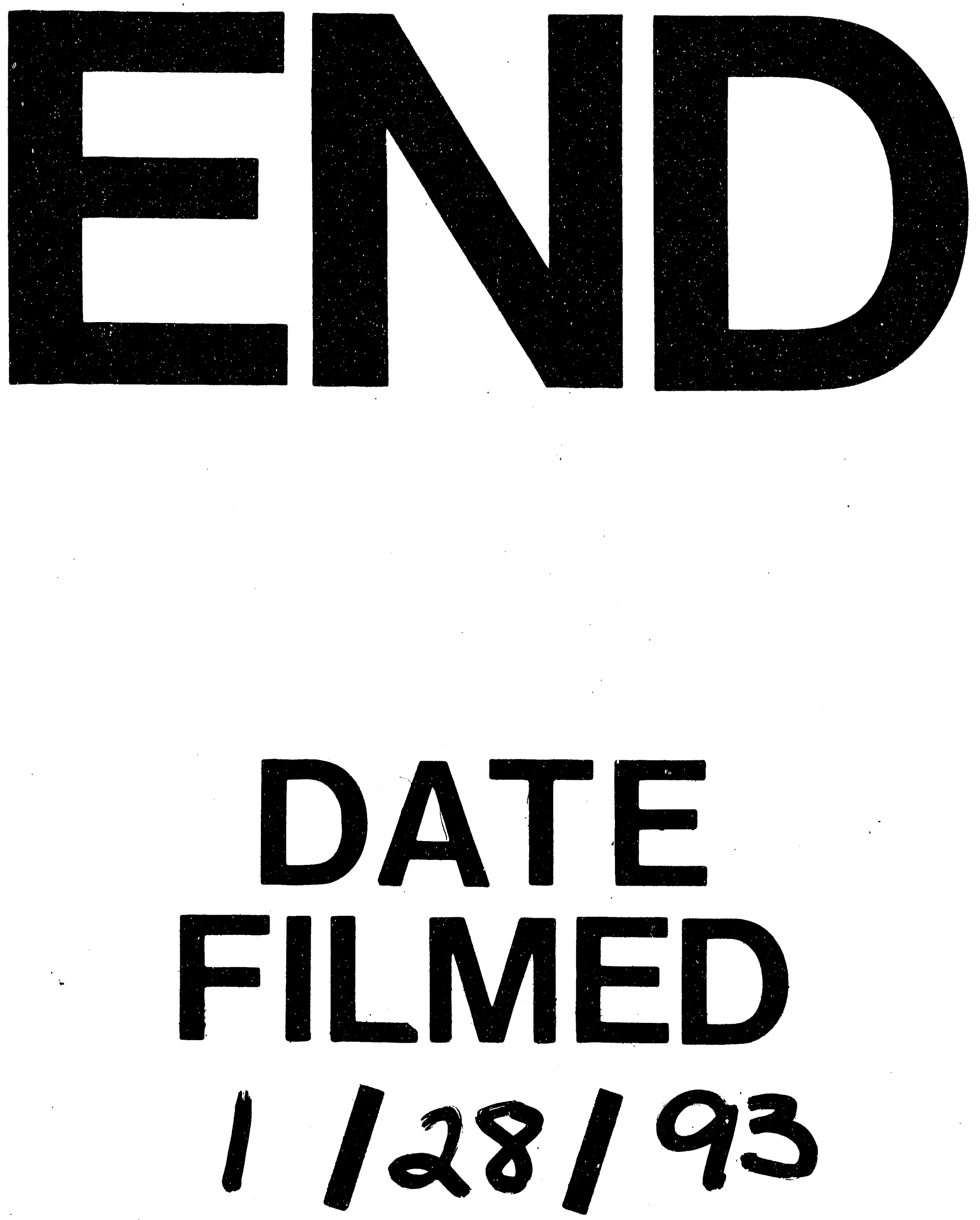
